\title{
Losing legs and walking hard: effects of autotomy and different substrates in the locomotion of harvestmen in the genus Prionostemma
}

\author{
Marisol Domínguez ${ }^{1}$, Ignacio Escalante ${ }^{2,12}$, Farah Carrasco-Rueda ${ }^{3,13}$, Cielo E. Figuerola-Hernández ${ }^{4}$, María Marta Ayup ${ }^{5}$, \\ María Natalia Umaña ${ }^{6}$, Daniel Ramos ${ }^{7}$, Arturo González-Zamora ${ }^{8,14}$, Carolina Brizuela ${ }^{9}$, Willy Delgado ${ }^{10}$ and Jessica \\ Pacheco-Esquivel ${ }^{11}$ : ${ }^{1}$ Departamento de Ecología, Genética y Evolución \& IEGEBA-CONICET, Facultad de Ciencias \\ Exactas y Naturales, Universidad de Buenos Aires, Buenos Aires, Argentina. E-mail: soldominguez@ege.fcen.uba.ar; \\ ${ }^{2}$ Escuela de Biología, Universidad de Costa Rica; ${ }^{3}$ Center for Conservation, Education and Sustainability, Smithsonian \\ Conservation Biology Institute, National Zoological Park, Washington DC, USA; ${ }^{4}$ Biology Department, University of \\ Puerto Rico at Río Piedras, San Juan, Puerto Rico; ${ }^{5}$ Instituto de Ecología Regional, Universidad Nacional de Tucumán, \\ Tucumán, Argentina; ${ }^{6}$ Department of Plant Biology, Michigan State University, East Lansing, Michigan, USA; \\ ${ }^{7}$ Universidad Laica Eloy Alfaro de Manabí-Manta. Manta, Ecuador; ${ }^{8}$ Instituto de Ecología A.C., Xalapa, Veracruz, \\ México; ${ }^{9}$ Escuela de Ciencias Biológicas, Universidad Nacional, Costa Rica; ${ }^{10}$ Museo de Historia Natural de la \\ Universidad Nacional de San Agustín de Arequipa, Perú; ${ }^{11}$ Pontificia Universidad Católica del Ecuador. Pichincha, \\ Ecuador; ${ }^{12}$ Current address: Department of Environmental Science, Policy, and Management. University of California, \\ Berkeley, USA; ${ }^{13}$ Current address: School of Natural Resources and Environment, University of Florida, Gainesville, \\ Florida, USA. ${ }^{14}$ Current address: Instituto de Investigaciones Biológicas, Universidad Veracruzana, Xalapa, Veracruz, \\ Mexico
}

\begin{abstract}
Autotomy, the strategy of voluntarily releasing a leg during an encounter with a potential predator or in agonistic interactions between conspecifics, is common in animals. The potential costs of this behavior have been scarcely studied. In addition, locomotion and substrate-dependent performance might be affected by autotomy. We did a comparative and observational study to investigate whether losing legs affects the escape speed and trajectory of harvestmen in the genus Prionostemma Pocock, 1903 (Eupnoi: Sclerosomatidae) on different substrates: soil (the least roughened), smooth bark and mossy bark (the most roughened) in a tropical premontane forest in Costa Rica. We observed that $71 \%$ of the individuals found were missing at least one leg. Harvestmen, regardless of leg condition, walked faster and made fewer turns in their trajectory in the soil. While climbing, they were faster on smooth bark than in moss. On all substrates, autotomized individuals were slower and had a more erratic trajectory than intact ones. The type of missing legs (sensory or locomotor) had no influence on the speed or trajectory. We experimentally induced autotomy and found that walking speed on soil decreases if individuals lose a leg. Our findings confirm that losing legs affects locomotion, and we provide novel insights on how locomotion in these harvestmen depends on surface roughness. Our data suggest that moss could be a type of substrate that requires more elaborate skills in balance, orientation and texture recognition than smooth bark.
\end{abstract}

Keywords: Costa Rica, Eupnoi, Opiliones, Sclerosomatidae

A wide variety of animals display defense mechanisms in which a body part or limb is voluntarily released. For instance, geckos (Congdon et al. 1974), lizards (Bellairs \& Bryant 1985), scorpions (Mattoni et al. 2015) and sea snails (Lewin 1970) selfamputate their tail when they feel threatened; while some crickets (Bateman \& Fleming 2005) and spiders (Eisner \& Camazine 1983) release a leg, a strategy known as autotomy. Autotomy enhances survival because the detached member can distract a predator allowing the animal to escape (Maginnis 2006). However, it may have direct costs in locomotion and the biomechanical performance of animals.

Current information about the effect of autotomy on the locomotion of animals suggests long-term costs in locomotion (Bateman \& Fleming 2005; Maginnis 2006; Combes et al. 2010). For example, tail loss in European wall lizards (Podarcis muralis) increased running speed and distance traveled but decreased their arboreal performance (Brown et al. 1995). Wrinn \& Uetz (2008) studied the effect of autotomy in the North American wolf spiders Schizocosa ocreata (Hentz, 1844 ) and found a reduction in prey capture rates. Harvestmen or "daddy long-legs" (Arachnida: Opiliones) of two Leiobunum species from North America (L. nigripes Weed, 1887 and
L. vittatum Say, 1821) showed reduction in walking and climbing speed, as well as in foraging ability, after losing up to three legs (Guffey 1999; Houghton et al. 2011). In Holmbergiana weyenberghi Holmberg, 1876 from Uruguay, individuals missing one sensory leg walked and climbed a log slower than individuals lacking locomotor legs or individuals with all of their legs (Escalante et al. 2013). These findings suggest that lacking sensory legs may confer greater costs in orientation, balance and substrate recognition.

Based on the different biophysical properties of the environment in which animals are found (Spagna et al. 2007), a substrate-dependent change in performance is expected. Substrate roughness can affect the locomotor performance or walking speed of cursorial animals (Spagna et al. 2007; Spence et al. 2010). Spagna et al. (2007) experimentally tested how differences in a two-dimensional terrain surface affected the running speed and locomotor performance in spiders (Hololena adnexa Chamberlin \& Gertsch, 1929), crabs (Ocypode quadrata Fabricius, 1787) and cockroaches (Periplaneta americana Linnaeus, 1758). The authors found that animals could attain high speed even when a substantial percentage of the terrain was experimentally removed (they removed up to $90 \%$ of the 
surface contact area in wire mesh), altering the probability of support and consequently, the stability and speed. All these arthropods did this by changing the orientation of their legs and using leg spines to improve contact with the surface (Spagna et al. 2007). In addition, a recent study showed that a species of beetle (Dendroctonus ponderosae Hopkins, 1902) presented better grip walking on smooth bark than on rough bark of pine trees (Ferrenberg \& Mitton 2014). Therefore, complex, intricate and three-dimensional substrates are expected to impose greater locomotor costs. However, this hypothesis remains untested. In our study, we investigated the effects of substrate complexity in natural conditions on locomotor performance of harvestmen that either had or had not suffered an autotomy event. Substrate complexity will ultimately have important consequences for biomechanical performance and fitness.

To achieve this, we tested three substrates commonly used by these harvestmen: soil, smooth bark and mossy bark. These substrates could be located in a scale of roughness with soil presenting the least roughness, smooth bark being located in the middle of the roughness scale, and mossy bark as the most roughened substrate.

Harvestmen are ideal organisms to study the effects of autotomy in locomotion because (1) autotomy is common (Roth \& Roth 1984; Guffey 1999; Gnaspini \& Hara 2007; Houghton et al. 2011), probably because harvestmen voluntarily release legs during a predator encounter or in male-male interactions (Macías-Ordoñez 1997; Fleming et al. 2007); and (2) they are not able to regenerate their legs (Kury 2000; Gnaspini \& Hara 2007). In sclerosomatid harvestmen, legs from pair I, III and IV are used for locomotion while the longest legs corresponding to pair II are primarily (but not exclusively) used for sensory functions (Shultz \& Pinto-da-Rocha 2007; Willemart \& Chelini 2007; but see Willemart et al. 2009).

Here we investigate two undescribed species of Prionostemma Pocock, 1903 in southwestern Costa Rica. Our research questions were: (1) How frequent is autotomy in these species? (2) Do the number and type of missing legs affect locomotion? and (3) Does locomotion of harvestmen differ in substrates with different complexity? For question two, we predicted that individuals with an incomplete number of legs would walk and climb more slowly than individuals with a complete (eight) number of legs, and individuals lacking locomotor legs would walk slower than individuals lacking sensory legs. We used two subsets of individuals captured in the wild: (a) individuals with variable numbers of legs, to test the effects in wild caught autotomized individuals, and (b) an experimental subset of intact individuals in which autotomy was induced, to test the immediate effect of losing legs on locomotor performance. For question three, we expected a change in substrate-dependent performance (both in speed and trajectory) in the substrates on which they are frequently found in the field (Escalante, Domínguez and Gómez-Ruíz, unpublished data). Our experimental design allowed us to test whether there is a greater cost of being in a rough substrate, such as moss (where the studied species commonly group and roost during the day; Escalante, Domínguez and Gómez-Ruíz, unpublished data), because a non-smooth surface could hinder the escape response of all harvestmen regardless of the number of missing legs.

\section{METHODS}

Study site.-We performed trials in Las Cruces Biological Station, San Vito de Coto Brus, Puntarenas province, Costa Rica ( $\left.8^{\circ} 47^{\prime} \mathrm{N}, 82^{\circ} 57^{\prime} \mathrm{W}\right)$, between $20-22$ January 2012; and between 19-21 January 2013. The site is a 300 ha pre-montane wet forest reserve (elevation $1200 \mathrm{~m}$; air temperature $13-26^{\circ} \mathrm{C}$; $4000 \mathrm{~mm}$ annual rainfall).

Field observations and experimental design.-We captured advanced juveniles and adult Prionostemma spp. harvestmen by hand along the Río Java, Melissa and Jungle trails. We did not determine the sex of individuals because this could have stressed them and affected their behavior. A total of 218 individuals were located mostly on tree trunks at $1-2 \mathrm{~m}$ height. Manipulation and observations were made during the day $(0900-1500 \mathrm{hrs})$. We placed individuals in plastic cubic containers $(30 \times 15 \times 15 \mathrm{~cm})$ with wetted cotton, leaves and branches for a minimum of $20 \mathrm{~min}$ before trials to acclimate.

We recorded the number and type of missing legs prior to capture. If a leg was lost during capture we did not consider that individual for the study. We conducted two different types of trials, the first with animals that had experienced autotomy naturally, and the second in which we induced autotomy.

For our first trials, we emulated an escape event from a predator, by holding the harvestmen and releasing it in a substrate in which it could escape by either running or walking. We studied if under these conditions the locomotor performance on different substrates varied according to the quantity and type of legs. The substrates were: (1) soil, a circular area on the ground of $1 \mathrm{~m}$ in diameter previously cleared of leaf litter and branches, (2) mossy bark and (3) smooth bark. The latter two substrates were $90 \times 30 \mathrm{~cm}$ quadrats on a vertical trunk with or without moss, each on a different tree of the same species that were $10 \mathrm{~m}$ apart. The same tree was used several times because we did not notice any behavioral indication that harvestmen were marking the substrate with chemical cues. We consider that our substrate categories reflect different roughness and complexity levels although this was not measured quantitatively.

We gently handled the harvestman by holding them by more than two legs to avoid inducing autotomy, and then carefully placed them in the middle of the experiment area, following Smith et al. (2012) and Escalante et al. (2013). Then, we measured the distance walked from the starting point to the edge of the arena, or to the place where they stopped for more than $10 \mathrm{~s}$. We also measured the time spent walking in order to calculate their speed. Regardless of the substrate, we use escape speed to refer to walking (soil) or climbing (moss or bark) no matter the direction (horizontal or vertical) of the movement (Escalante et al. 2013). As another indication of their escape performance, we estimated their trajectory by measuring the number of times an individual changed its direction, and divided the number of changes of direction by the distance walked. We considered a greater number of turns to be associated with poor performance, as suggested by Escalante et al. (2013), under the assumption that maintaining a straight line during escape would be beneficial. We calculated the speed of 142 individuals, and the trajectory in 104 individuals. Due to logistic reasons, a subset of individuals only walked in the soil, whereas another subset was tested in both moss and bark, and we randomly alternated which substrate they climbed 
first. We did not find an effect of order while alternating the substrate (moss or bark) on which harvestmen walked first (speed: Mann-Whitney $U=1880.0, P=0.83$; trajectory: $U=$ 1844.0, $P=0.70)$. Smith et al. (2012) found leg length to be important for locomotion when comparing species of different families. Therefore, to test whether leg length affects the speed or trajectory, we measured the length $( \pm 0.1 \mathrm{~mm})$ of one leg IV of 74 individuals.

In a second subset of trials, we experimentally tested the effect of autotomy. First, those individuals were tested for walking performance on soil, as described above. Then we induced leg autotomy on 23 eight-legged harvestmen by carefully holding them upside down by the femur of a given leg, following Houghton et al. (2011). One leg of the pair II (sensory leg) was released in 10 individuals while one from pair I (locomotor leg) was released in 13 individuals. Five minutes after autotomy, we took a second measure of their walking speed on soil.

Statistical analysis.-All the analyses were conducted with STATISTICA 8.0 (StatSoft, Inc. 2007). To test whether the length of leg IV affects the speed or trajectory of individuals in the mossy bark and smooth bark substrate, we conducted simple linear regressions. We found no significant effect of leg length on speed $\left(r^{2}=-0.08, P=0.38, n=124\right)$, or trajectory $\left(r^{2}=0.05, P=0.62, n=104\right)$, thus, we did not include leg length in further analyses of locomotor performance.

Our two measures of harvestmen locomotion (escape speed and trajectory; see above) allowed us to investigate the overall effect of autotomy. Although we found a significant negative correlation between these two variables $\left(r=-0.45 ; F_{1 / 102}=\right.$ 27.29; $P<0.001$ ), we present results of both because we consider these measurements to provide a more integrative description of their locomotion. Also, both variables may elucidate the locomotor constraints that autotomized individuals experience depending on the substrate type.

To investigate the factors that influence escape speed and trajectory, we constructed models with three predictor variables: number of legs, type of missing legs (if any), and substrate where each individual walked. The type of missing leg included three categories: (a) individuals with all of their legs, (b) individuals lacking at least one locomotor leg, and (c) individuals lacking at least one sensory leg. Individuals lacking a combination of leg types (sensory and locomotor) were not considered for the trails. The substrate included three categories: soil, smooth bark, and mossy bark. We performed generalized linear models (GLM) to evaluate the effect of the type and number of missing legs and the type of substrate on speed and trajectory. These response variables were analyzed using two GLMs with normal error distribution and an identity link function. Data were tested for normality and heteroscedasticity, showing that assumptions were not violated for speed or for trajectory. For speed, data followed a normal distribution in the QQplot but Shapiro Wilks test was marginally significant ( $W=0.97, P=0.05$ ). Also, the variance between the groups seems to be homogeneous when inspected both visually and analytically (Levenne test $F=1.28, P=0.23$ ). For trajectory, data seemed to follow a normal distribution in the QQplot and also in Shapiro Wilks test $(W=0.97, P=0.48)$. Also, the variance between the groups seemed to be homogeneous when inspected both visually and analytically (Levenne test $F=1.39, P=0.16$ ).

To test the effect of induced autotomy, we analyzed the speed before and after autotomy with a paired t-test since the differences between before and after were normally distributed (Shapiro Wilks test $W=0.91, P=0.14$ ). Additionally, to test if the type of missing legs affects speed immediately after autotomy we calculated the differences in the pairs (speed after and before autotomy) and carried out a t-test on the differences comparing the speed between the two treatments (lost sensory leg and lost locomotor leg).

Prionostemma is a taxonomically unresolved genus, and many papers have reported behavioral and ecological data without being able to identify them to the species level (Wade et al. 2011; Proud et al. 2012; Smith et al. 2012; Teng et al. 2012; Grether et al. 2014a, b). In our trials, we used two morphospecies (red and black: Escalante, Domínguez and Gómez-Ruíz, unpublished data), potentially two new species. However, because they did not differ in leg IV length $\left(T_{120}=\right.$ $0.69 ; P=0.49$ ) or walking speed or trajectory (walking speed: $T_{153}=-0.46 ; P=0.64$. trajectory: $\left.T_{100}=0.15 ; P=0.88\right)$, we grouped the data of both morphospecies for our analyses.

\section{RESULTS}

We found that $29 \%$ of 157 individuals had all of their legs, $29 \%$ of the autotomized individuals lacked at least one leg from pair II (sensory legs), and a lower frequency of individuals lacked locomotor legs (pair I: $17 \%$, pair III: $10 \%$ and pair IV $15 \%$ ). These percentages are non-exclusive, meaning that individuals could be missing legs from more than one pair. Lacking a leg from pair II was more frequent than expected by chance $\left(X_{3}^{2}=21.98, P<0.001\right)$. We also found harvestmen unevenly distributed in various substrates in the field; from a total of 62 groups, $68 \%$ were in mossy trees and lianas, $13 \%$ on smooth bark, $2 \%$ on the soil, and the remaining in foliage $\left(X^{2}{ }_{4}=91.4\right.$, $P<0.0001)$. Additionally, we randomly chose 22 trees in which we found Prionostemma, and 14 (64\%) of them had extensive moss cover.

Escape speed and trajectory.-Escape speed was affected by the number of legs (Fig. 1) and the type of substrate, but not by the type of missing leg (Fig. 2). Autotomized individuals had slower speed than intact individuals (GLM: Wald $X^{2}=$ 5.93, df $=1, P=0.01$, Fig. 1A). Also, individuals walked faster on the soil than on smooth bark, and climbed slower on the mossy bark substrate (GLM: Wald $X^{2}=21.07$, df $=2, P<$ 0.001 , Fig. 1A). When analyzing the type of missing leg, the pattern was less clear. Lacking sensory or locomotor legs had no effect on speed (GLM: Wald $X^{2}=1.81$, df $=2, P=0.40$, Fig. 2A). Also, there was no interaction between the type of substrate and the type of missing legs on their escape speed (GLM: type of missing legs*substrate type speed [GLM: Wald $X^{2}=8.79$, $\left.\left.\mathrm{df}=4, P=0.07\right]\right)$.

Trajectory was also affected by the number of legs and the type of substrate (Fig. 1B), but not by the type of missing leg (Fig. 2B). Autotomized individuals made more turns in their trajectory than intact individuals (GLM: Wald $X^{2}=4.73$, df $=1, P=0.03$, Fig. 1B). Individuals made more turns per distance on mossy bark or smooth bark than on soil (GLM: Wald $X^{2}=47.66$, df $=2, P<0.001$, Fig. 1B). The number of turns did not differ with the type of missing leg (sensory 

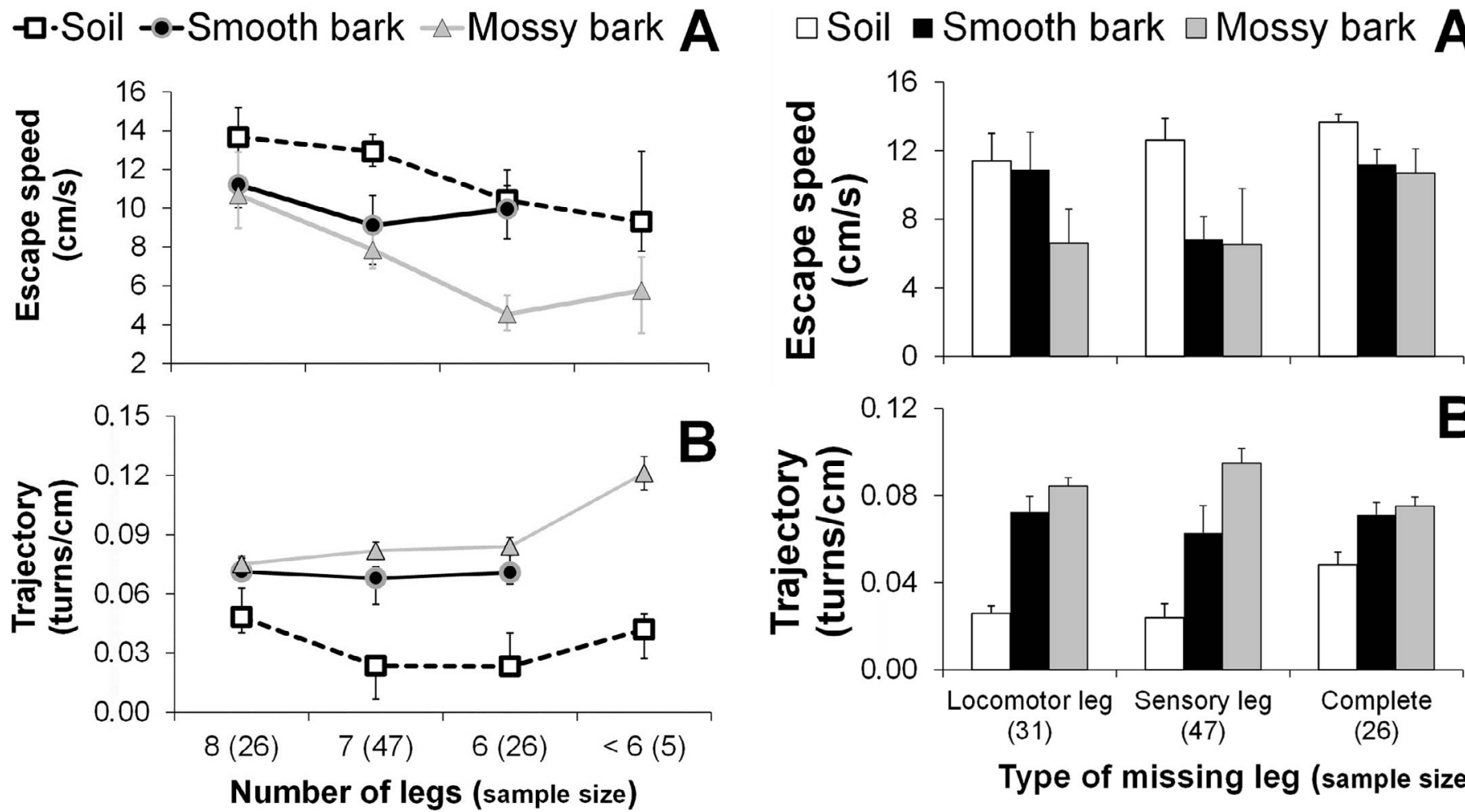

Type of missing leg (sample size)

Figure 1.-(A) Escape speed mean ( \pm standard error) and (B) trajectory ( \pm standard error) of Prionostemma spp. on different substrates, according to the number of legs. The sample size for each category is included in parenthesis.

versus locomotor legs) (GLM: Wald $X^{2}=3.45, \mathrm{df}=2, P=$ 0.178 , Fig. 2B), and there was no interaction between the type of legs and the type of substrate (GLM: Wald $X^{2}=5.14$, $\mathrm{df}=4, P=0.28$, Fig. 2B).

Pairwise comparisons, considering all individuals with and without a complete set of legs $(n=65)$, revealed that individuals climbed slower and with a more erratic trajectory (more turns) on mossy bark (mean velocity: $7.28 \mathrm{~cm} / \mathrm{s}$, mean trajectory: 0.08 turns $/ \mathrm{cm}$ ) and smooth bark (mean velocity: $9.12 \mathrm{~cm} / \mathrm{s}$, mean trajectory: 0.07 turns $/ \mathrm{cm}$ ) than on soil (mean velocity: $12.09 \mathrm{~cm} / \mathrm{s}$, mean trajectory: 0.03 turns/cm; Tukey tests $P<0.05$ ) (Fig. 1).

Overall, harvestman speed decreased on average by $21 \%$ following autotomy of a leg (paired t-test $=2.33$, $\mathrm{df}=22$, $P=0.03$, Fig. 3). Regarding the type of leg missing, recently autotomized individuals that had lost a locomotor leg showed a greater overall change in their escape speed (mean $=6.45$ $\mathrm{cm} / \mathrm{s})$ than the ones that lost a sensory leg $($ mean $=0.63 \mathrm{~cm} / \mathrm{s})$ (Fig. 4), although our test was marginally significant (t-test conducted with the differences before-after autotomy $=2.07$, $\mathrm{df}=21, P=0.054)$.

\title{
DISCUSSION
}

In this study we found that harvestmen had greater speed on the soil, and climbed faster on smooth bark than on mossy bark. Furthermore, autotomized individuals were slower than intact individuals, regardless of which leg was lost. Our finding that individuals climbing on mossy bark and autotomized individuals had more erratic trajectories, demonstrates that harvestmen exhibit both substrate-dependent and autotomy-
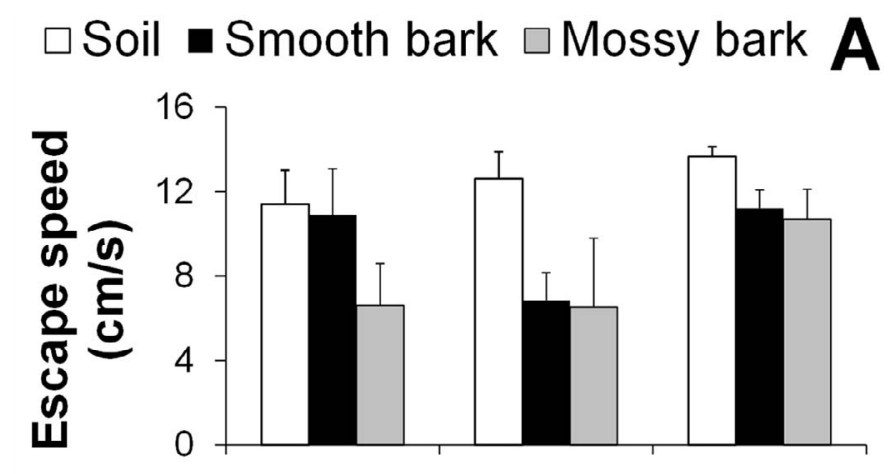

\begin{abstract}
Figure 2.-(A) Escape speed mean (+ standard error) and (B) trajectory (+ standard error) of Prionostemma spp. on different substrates, according to the type of legs missing. The sample size for each category is included in parenthesis.
\end{abstract}

dependent trajectory patterns. We also found that missing legs (of any type) influenced their locomotion across all three substrates tested. All together, these results provide novel insights into the potential effect of substrate type on the locomotion performance of invertebrates. Appropriate substratedependent performance is likely to affect predatory avoidance

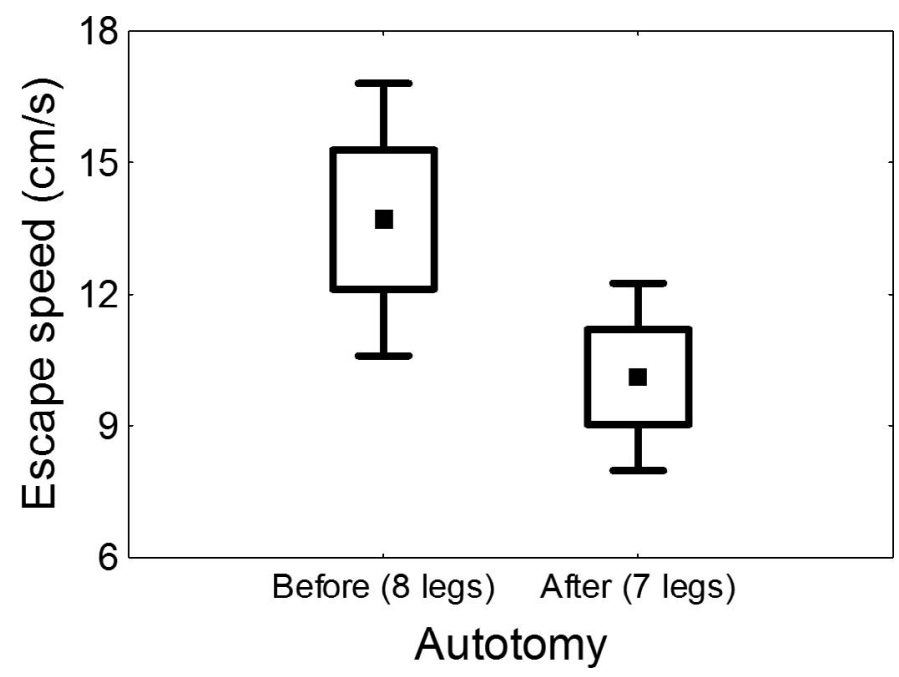

Figure 3.-Escape speed of Prionostemma spp. on soil before and after inducing autotomy; individuals had eight and seven legs in the trials, respectively. The same individuals were tested in both contexts, in a paired design. Box plots depict the mean (black square), standard error (box), and maximum and minimum values (whiskers). 


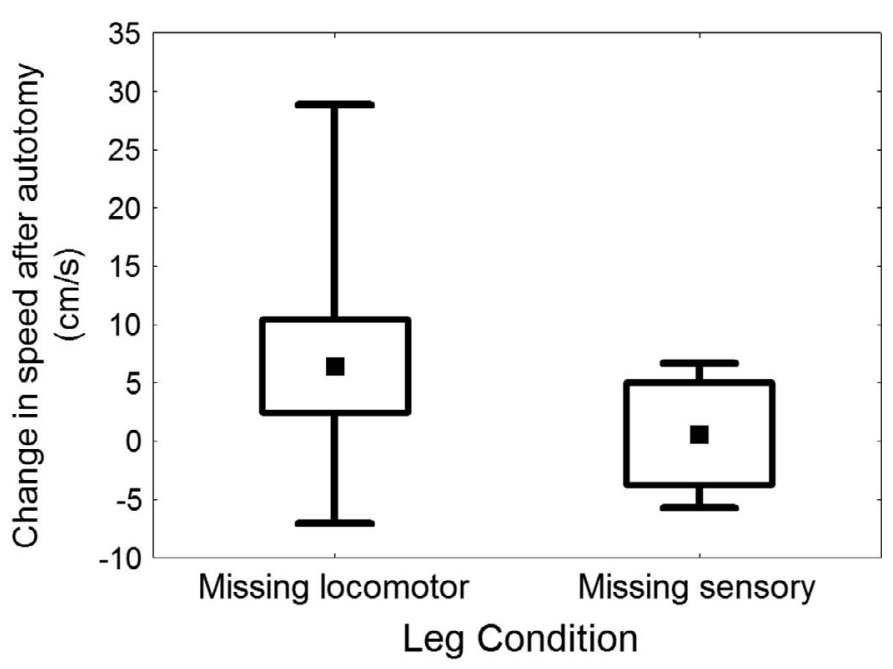

Figure 4.- Change in speed of Prionostemma spp. on soil after autotomy, depending on the type of leg lost. The change in speed was calculated as the difference between the speed before the experiment and the speed 5 minutes after we induced autotomy of one leg. Box plots depict the mean (black square), standard error (box), and maximum and minimum values (whiskers).

and escape success. Our results suggest that arthropods have differential performance according to different substrates, and, although speculative, we consider that this could mediate their substrate use and/or selection.

Surprisingly, our results show that Prionostemma spp. had worse locomotor performance on the substrate they most frequently use to group and roost during the day (mossy bark) compared with the other substrates. The complex three-dimensional structure of the mossy bark substrate might represent a more challenging surface to navigate compared to the smooth bark and soil substrates (see Spagna et al. 2007). Moreover, the potential benefits of thermoregulation and crypsis of the mossy bark substrate might be compromised if harvestmen acquire a poorer locomotor performance. However, to date information of this kind remains unknown. By studying microhabitat selection in intact and autotomized individuals and expanding on the potential benefits of the grouping sites, research will yield important insights on the costs of autotomy for animals.

Slower speed in the preferred substrate likely indicates a cost in terms of their ability to escape from predation events in the mossy bark. Thus, these harvestmen may rely primarily on their grouping ability and crypsis as anti-predatory tactics (Gnaspini \& Hara 2007). Nonetheless, the predation pressure on the substrates in which they roost is unknown. Prionostemma spp. and other sclerosomatid harvestmen are likely to experience predation attempts during the day while roosting in either mossy bark or smooth bark substrates of trees. Additionally, they will encounter predators at night while foraging on the foliage and on the ground (soil substrate). Hence, we are confident that our trials represent biologically relevant situations in which Prionostemma spp. attempt to escape a predator by autotomizing legs. In our trials, we tested harvestmen in two different biomechanical contexts: horizontal and vertical locomotion; thus, it is possible that the effect of gravity in vertical substrates could partially explain why individuals walked slower in the trees (either mossy bark or smooth bark trials) than on the soil. However, because there were also differences between the two vertical substrates (mossy bark and smooth bark), we do not consider gravity to be a confounding factor. Further studies should emphasize the possible effects of gravity by repeating these tests with all three substrates on the same plane. Furthermore, individuals made more turns per distance on mossy bark or smooth bark than on soil. This could be the result of orientation facilitated by gravity on vertical surfaces. A trade-off could be mediating locomotor performance. On the one hand, on vertical surfaces harvestmen could be investing more energy in looking for a previously used path by other individual through the detection of chemical cues (Willemart et al. 2009) or looking for leaves, twigs or branches to grab on, especially giving the prehensile tarsal capacities sclerosomatid harvestmen have (Guffey et al. 2000). On the other hand, while walking on horizontal surfaces, in this case the soil, escape to the nearest vertical surface would be prioritized, aiming to navigate in more complex three-dimensional environments wherein escape or crypsis is favored.

Our finding that autotomy was associated with a more erratic trajectory could be due to either a mechanical by-product of lacking legs, or a behavioral strategy to compensate for that loss. The differences in trajectory between intact and autotomized individuals suggest a cost to balance in individuals with different number of legs on each side of their body. Body symmetry can play an important role: having more legs on one side of the body could alter their balance by decoupling the hexapod-like alternating gate performed by sclerosomatid harvestmen (Sensenig \& Shultz 2006) while walking. In the case of a behavioral strategy, a zigzagging locomotion may confuse a potential predator and increase the harvestman's probability of escape (Gnaspini \& Hara 2007).

So far, little research has focused on the effect of autotomy in harvestmen and the few studies have uncovered different patterns. Previous findings indicate that leg loss causes a reduction in walking and climbing speed (Houghton et al. 2011), and foraging ability (Guffey 1999). Sensenig \& Shultz (2006) showed that sensory legs do not participate directly in locomotion. In our study, we did not find any effect of leg type or leg IV length on locomotion, in contrast to the findings of Escalante et al. (2013). Potential differences in social structure and grouping behaviors, as well as environmental factors such as the roosting site, predation pressure or foraging efficiency could account for the differences found between studies.

Our experiments demonstrated that harvestmen travel at different speeds depending on the number of legs present. When we compared the escape speed of seven legged-individuals (after removing a sensory or locomotor leg) versus their initial speed, we found that a decrease in walking speed occurred, and we found partial support to the fact that losing a locomotor leg is more costly since it conveys a greater decrease in speed, contrary to Escalante et al. (2013). Overall, losing a leg seems to have an immediate effect on locomotion. Although we did not repeatedly test intact individuals to account for any variation they may exhibit in walking speeds, prior to inducing autotomy, our experimental results showed a clear pattern (a decrease in walking speed after losing a leg). The negative effect of experimentally induced autotomy on locomotion coupled with our finding that $42 \%$ of individuals lost at least a 
locomotor leg prior to their capture for this study, highlights the prevalence and potentially great cost that autotomy has in locomotion, especially in the escape response.

Another finding was that lacking a sensory leg was more frequent than expected by chance. This frequent loss can be attributed to the fact that the long sensory legs are used to palpate and to obtain information about the surroundings. Spagna et al. (2007) noted that arthropods get mechanical feedback from the substrates in which they walk, which could be associated with efficient performance. Consequently, if harvestmen lose their sensory legs, they would be more exposed to a predator attack. In addition to the escape response from predators, harvestmen may also lose the legs of pair II more often simply because they are the longest, and the trochanter-femur joint must be under tension and thus, could be easier to break. The costs of losing certain legs could be asymmetrical. We found fewer individuals without legs from pair III (10\%), and many individuals missing leg II and leg I (29\% and 17\%, respectively). In this study we induced autotomy to a leg I or II in order to have an appropriate comparison and sample size, and also because those were the two most frequently lost legs. However, the findings concerning leg I should not be extrapolated to the other locomotor legs (III and IV). The asymmetry in autotomy might suggest differential costs of losing legs I, III and IV. For instance, during the alternate tripod gait, leg III of one side moves simultaneously with legs I and IV from the other side (Sensenig \& Shultz 2006). If any leg III is to be lost, the coordination and performance of the locomotion would potentially be more affected than if a leg I or IV were lost. So, according to our results, leg III is lost less frequently but this could be because it is the most expensive to lose because it may be more crucial for walking than is a leg I or IV, or simply because it is the shorter and less accessible (Shultz \& Pinto-da-Rocha 2007). Future research should focus on the importance of each leg in locomotion biomechanics, as well as to test how willing harvestmen are to release legs from each pair (our preliminary observation suggests asymmetry in that trait also), in order to elucidate the context-specific costs of autotomy.

Additionally, further research on the effects of autotomy on sexual behavior is needed in order to understand the fitness consequences of this anti-predatory tactic. Fowler-Finn et al. (2014) found that the access to mating by males of the North American sclerosomatid L. vittatum was mediated by their courting behavior, particularly tapping and grabbing the female's leg II with legs III. Therefore, missing legs can have negative consequences for Eupnoi harvestmen. However, another sclerosomatid (Nelima paessleri Roewer, 1910) was seen mating when both male and female were missing legs (Escalante, unpublished data). Future research can provide specific information on how the fine scale details of the courtship, mating, and sperm transfer are affected by autotomy, in both sexes. Even though autotomized harvestmen can mate, probably the rate of mating success, the time spent in courting and other reproductive tasks are compromised.

In summary, impaired locomotor performance likely translates into decreased survivorship or decreased ability to forage/capture prey or escape from predators. Harvestmen seem to use autotomy to increase their survival (Gnaspini \& Hara 2007); however, our findings implicate a tradeoff cost in their escape speed. Our research contributes to the understanding of the prevalence of autotomy in Prionostemma spp. harvestmen and of how the number of missing legs and the substrate type affect locomotion. By comparing the speed and trajectory of individuals with different numbers of legs in various natural environments, this study provides the first description of the effect of substrate in locomotion performance.

\section{ACKNOWLEDGMENTS}

We thank A.G. Farji-Brener, F. Chinchilla, and G. Barrantes for their assistance in the design, analysis and interpretation of this project. E. Triana provided great suggestions to improve the project, as well as field assistance. We thank the Organization for Tropical Studies and Las Cruces Biological Station for providing housing, logistics, transportation and financial support during this project. V.R. Townsend, Jr., Joel Wixson, Elizabeth C. Braun, and two anonymous reviewers provided useful comments to improve this project. The Biology Department of the UPR at Río Piedras provided financial support to CF. The Universidad de Antioquia, Colombia provided financial support to DG-R, and the Center For Conservation Education and Sustainability, Smithsonian Conservation Biology Institute and CONCYTEC for the financial support to FC-R.

\section{LITERATURE CITED}

Bateman, P.W. \& P.A. Fleming. 2005. Direct and indirect costs of limb autotomy in field crickets, Gryllus bimaculatus. Animal Behaviour 69:151-159.

Bellairs, A.D. \& S.V. Bryant. 1985. Autotomy and regeneration in reptiles. Pp. 301-410. In Biology of the Reptilia, Vol. 15: Development B. (C. Gans, F. Billet, eds.). John Wiley and Sons, New York.

Brown, R.M., D.H. Taylor \& D.H. Gist. 1995. Effect of caudal autotomy on locomotor performance of wall lizards (Podareis muralis). Journal of Herpetology 29:98-105.

Combes, S.A., J.D. Crall \& S. Mukherjee. 2010. Dynamics of animal movement in an ecological context: dragonfly wing damage reduces flight performance and predation success. Biology Letters 6:426-429

Congdon, J.D., L.J. Vitt \& W.W. King. 1974. Geckos: adaptive significance and energetics of tail autotomy. Science 184:1379-1380.

Eisner T. \& S. Camazine. 1983. Spider leg autotomy induced by prey venom injection: An adaptive response to "pain"? Proceedings of the National Academy of Sciences USA 80:3382-3385.

Escalante, I., A. Albín \& A. Ainseberg. 2013. Effect of leg loss on locomotion and food detection speeds in the harvestman Holmbergiana weyenberghi (Sclerosomatidae, Opiliones). Canadian Journal of Zoology 91:726-731.

Ferrenberg, S. \& J.B. Mitton. 2014. Smooth bark surface can defend trees against insect attack: resurrecting a "slippery" hypothesis. Functional Ecology 28:837-845.

Fleming, P.A., D. Muller \& P.W. Bateman. 2007. Leave it all behind: a taxonomic perspective of autotomy in invertebrates. Biological Reviews 82:481-510.

Fowler-Finn, K.D., E. Triana, \& O.G. Miller. 2014. Mating in the harvestman Leiobunum vittatum (Arachnida: Opiliones): from premating struggles to solicitous tactile engagement. Behaviour 151:1663-1686.

Gnaspini, P. \& M.R. Hara. 2007. Defense Mechanisms. Pp. 374-399. In Harvestmen: The Biology of Opiliones. (R. Pinto-Da-Rocha, G. Machado, G. Giribet, eds.). Harvard University Press, Cambridge, Massachusetts. 
Grether, G.F., T.L. Aller, N.K. Grucky, A. Levi, C.C. Antaky \& V.R. Townsend. 2014a. Species differences and geographic variation in the communal roosting behavior of Prionostemma harvestmen in Central American rainforests. Journal of Arachnology 42:257-267.

Grether, G.F., A. Levi, C. Antaky \& D.M. Shier. 2014b. Communal roosting sites are potential ecological traps: experimental evidence in a Neotropical harvestman. Behavioral Ecology and Sociobiology 68:1629-1638.

Guffey, C. 1999. Costs associated with leg autotomy in the harvestmen Leiobunum nigripes and Leiobunum vittatum (Arachnida: Opiliones). Canadian Journal of Zoology 77:824-830.

Guffey, C., V.R. Townsend Jr. \& B.E. Felgenhauer. 2000. External morphology and ultrastructure of the prehensile region of the legs of Leiobunum nigripes (Arachnida, Opiliones). Journal of Arachnology 28:231-236.

Houghton, J.E., V.R. Townsend Jr. \& D.N. Proud. 2011. The ecological significance of leg autotomy for climbing temperate species of harvestmen (Arachnida, Opiliones, Sclerosomatidae). Southeastern Naturalist 10:579-590.

Kury, A.B. 2000. Classification of opiliones. Museu Nacional/UFRJ website. Online at http://www.museunacional.ufrj.br/mndi/Aracnologia/ opiliones.html

Lewin, R.A. 1970. Toxin secretion and tail autotomy by irritated Oxynoe panamensis (Opisthobranchiata: Sacoglossa). Pacific Science 24:356-358.

Macías-Ordóñez, R. 1997. The mating system of Leiobunum vittatum Say 1821 (Arachnida: Opiliones: Palpatores): resource defense polygyny in the striped harvestman. Ph.D. dissertation. Lehigh University, Pennsylvania.

Maginnis, T.L. 2006. The costs of autotomy and regeneration in animals: A review and framework for future research. Behavioral Ecology 17:857-872.

Mattoni, C.I., S. García-Hernández, R. Botero-Trujillo, J.A. Ochoa, A.A. Ojanguren-Affilastro et al. 2015. Scorpion sheds 'tail' to escape: consequences and implications of autotomy in scorpions (Buthidae: Ananteris). PLoS ONE 10(1):e0116639.

Proud, D.N., B.E. Felgenhauer, V.R. Townsend, D.O. Osula, W.O. Gilmore \& Z.L. Napier et al. 2012. Diversity and habitat use of Neotropical harvestmen (Arachnida: Opiliones) in a Costa Rican rainforest. ISRN Zoology 2012:1-16.
Roth, V.D. \& B.M. Roth. 1984. A review of appendotomy in spiders and other arachnids. Bulletin of the British Arachnological Society 6:137-146.

Sensenig, A.T. \& J.W. Shultz. 2006. Mechanical energy oscillations during locomotion in the harvestman Leiobunum vittatum (Opiliones). Journal of Arachnology 34:627-633.

Shultz, J.W. \& R. Pinto-da-Rocha. 2007. Morphology and Functional Anatomy. Pp. 14-61. In Harvestmen: The Biology of Opiliones. (R. Pinto-Da-Rocha, G. Machado, G. Giribet, eds.). Harvard University Press, Cambridge, Massachusetts.

Smith, A.T., D.R. Cook, M.B. Johnson, V.R. Townsend Jr. \& D.N. Proud. 2012. Comparative study of walking and climbing speeds among Neotropical harvestmen from Costa Rica. Journal of Arachnology 40:304-308.

Spagna, J.C., D.I. Goldman, P.C. Lin, D.E. Koditschek \& R.J. Full. 2007. Distributed mechanical feedback in arthropods and robots simplifies control of rapid running on challenging terrain. Bioinspiration \& Biomimetics 2:9-18.

Spence, A.J., S. Revzen, J. Seipel, C. Mullens \& R.J. Full. 2010. Insects running on elastic surfaces. Journal of Experimental Biology 213:1907-1920.

Teng, B., S. Dao, Z.R. Donaldson \& G.F. Grether. 2012. New communal roosting tradition established through experimental translocation in a Neotropical harvestman. Animal Behaviour 84: $1183-1190$.

Wade, R.R., E.M. Loaiza-Phillips, V.R. Townsend \& D.N. Proud. 2011. Activity patterns of two species of Neotropical harvestmen (Arachnida: Opiliones) from Costa Rica. Annals of the Entomological Society of America 104:1360-1366.

Willemart, R.H. \& M.C. Chelini. 2007. Experimental demonstration of close range olfaction and contact chemoreception in the Brazilian harvestman, Iporangaia pustulosa. Entomologia Experimentalis et Applicata 123:73-79.

Willemart, R.H., J. Farine \& P. Gnaspini. 2009. Sensory biology of Phalangida harvestmen (Arachnida, Opiliones): a review, with new morphological data on 18 species. Acta Zoologica 90:209-227.

Wrinn, K.M. \& G.W. Uetz. 2008. Effects of autotomy and regeneration on detection and capture of prey in a generalist predator. Behavioral Ecology 19:1282-1288.

Manuscript received 30 January 2015, revised 25 August 2015. 